\title{
Land Surface Temperature in Response to Land Use/Cover Change Based on Remote Sensing Data and GIS Techniques: Application to Saïss Plain, Morocco
}

\author{
Manal El Garouani ${ }^{*}$, Mhamed Amyay ${ }^{2}$, Abderrahim Lahrach $^{3}$, Hassane Jarar Oulidi ${ }^{4}$ \\ 1 Sidi Mohamed Ben Abdallah University, FST-Fez, Route d'Imouzzer, Fez, B.P. 2202, Morocco \\ 2 Sidi Mohamed Ben Abdallah University, FLSHS, Fez, Morocco \\ 3 Sidi Mohamed Ben Abdallah University, ENSA, Fez, Morocco \\ 4 Hassania School for Public Works Engineering, Casablanca, Morocco \\ * Corresponding author's email: manalgarouani@yahoo.fr
}

\begin{abstract}
In order to analyze the impact of land use and land cover change on land surface temperature (LST), remote sensing is the most appropriate tool. Land use/cover change has been confirmed to have a significant impact on climate through various aspects that modulate LST and precipitation. However, there are no studies which illustrate this link in the Fez-Meknes region using satellite observations. Thus, the aim of this study was to monitor LST as a function of the land use change in the Saïss plain. In the study, 12 Landsat images of the year 2019 (one image per month) were used to represent the variation of LST during the year, and 2 images per year in 1988, 1999 and 2009 to study the interannual variation in LST. The mapping results showed that the land use/cover in the region has undergone a significant evolution; an increase in the arboriculture and urbanized areas to detriment of arable lands and rangelands. On the basis of statistical analyses, LST varies during the phases of plant growth in all seasons and that it is diversified due to the positional influence of land use type. The relationship between LST and NDVI shows a negative correlation (LST decreases when NDVI increases). This explains the increase in LST in rangelands and arable land, while it decreases in irrigated crops and arboriculture.
\end{abstract}

Keywords: land surface temperature, land use/cover, NDVI, landsat image, saïss plain, Morocco.

\section{INTRODUCTION}

For several years, satellite observation has been used to understand several phenomena on the Earth's surface. Considering the issues on global change, The characterization of dynamics linked to the earth's surface transformations, for example: the extension of agricultural areas, desertification, urban sprawl, etc. are essential. In this sense, much effort has been devoted to the determination of land surface temperature from the remote sensing data. Several authors have worked on LST determination by remote sensing for many purposes (Li et al., 2013; Qin Karnieli, 1999; Schmugge et al., 2002; Zhou et al., 2012). For example: evapotranspiration modelling (Courault et al., 2005), soil moisture estimation
(Sajjad et al., 2010), climatic, hydrological, ecological and biogeochemical studies (Bhaga et al., 2020) are based on the knowledge of the land surface temperature. Therefore, it is very important to have access to reliable LST estimation at large spatial and temporal scales. It is practically impossible to obtain such information from field measurements, whereas satellite observations in thermal infrared are very attractive because they give the access to spatio-temporal data for LST determination. Monitoring the changes in land cover/cover (LULC) in a given period at regional scale is one of the main requirements for climate change analysis and LST is the most important environmental parameter used to determine the energy and matter exchange between the earth's surface and the lower layer of the atmosphere 
(Feddema et al., 2005). Land cover change has been confirmed to have a significant impact on climate through various aspects that modulate LST and precipitation (Joshi et 2020; Yagoub, 2015). Several studies are based on the vegetation index and LST for the determination of soil moisture and vegetation water stress (Joshi et al., 2020; Nivedha et al., 2017; Yu and Cheng, 2010). However, there are no studies illustrating this link in the Fez-Meknes region using satellite observations. This paper concerns the use of remote sensing data and GIS for the study of the relationship between the land surface temperature and land use/cover in the Saïss plain during the period from 1988 to 2019.

\section{MATERIALS AND METHODS}

\section{Study area}

Saïss plain with an area of about $2260 \mathrm{~km}^{2}$, with $95 \mathrm{~km}$ length and $30 \mathrm{~km}$ width, is located in northern Morocco between the Lambert coordinates: $460<\mathrm{X}<553 \mathrm{~km}$ and $335<\mathrm{Y}<385 \mathrm{~km}$ (Figure 1). This plain occupies an important part of the Sebou watershed and is home to two of its largest cities (Fez and Meknes) and several Centers. The Saïss plain is characterized by a low topography decreasing from South to North, varying between $250 \mathrm{~m}$ and $600 \mathrm{~m}$. The region is drained by numerous rivers, of which Oued Fez and Oued Mekkes as well as their tributaries are the most important. However, on the past two decades, the region has experienced a decline in water resources manifested in reduced flows due to decreased rainfall. On the other hand, in the Saiiss plain, there is the overexploitation of water resources which is the main cause of the drop in flow and water table levels. The climate of the region is dry and hot in summer and humid and cool in winter with significant seasonal thermal differences and average rainfall of $500 \mathrm{~mm}$ in $\mathrm{Fez}$ and $600 \mathrm{~mm}$ in Meknes. The population of the FezMeknes basin is around two million and is growing continuously at 3 to $5 \%$ per year. Agriculture is the main economic activity in the Saïss plain.

\section{Data set}

In the framework of this study, 18 images produced by Landsat 5, 7 and 8 satellites were used (Table 1). Satellite images have a pre-processing level (Collection 1 level 1) (USGS, 2019a). They are in the form of a quantified and calibrated digital count representing the multispectral image data. The landsat 8 data acquired by both the Operational Land Imager (OLI) and the Thermal Infrared Sensor (TIRS) are provided in integer (16-bit) format. Landsat 5 and 7 products are provided in integer (8-bit) format.

\section{Extraction of physical parameters from Landsat images}

For LULC mapping and LST extracting from Landsat imageries, the following steps have been followed (Figure 2).

\section{Conversion of the digital count (DN) to spectral radiance $(L \lambda)$ at the satellite level}

Each object emits thermal electromagnetic energy, because its temperature is above absolute

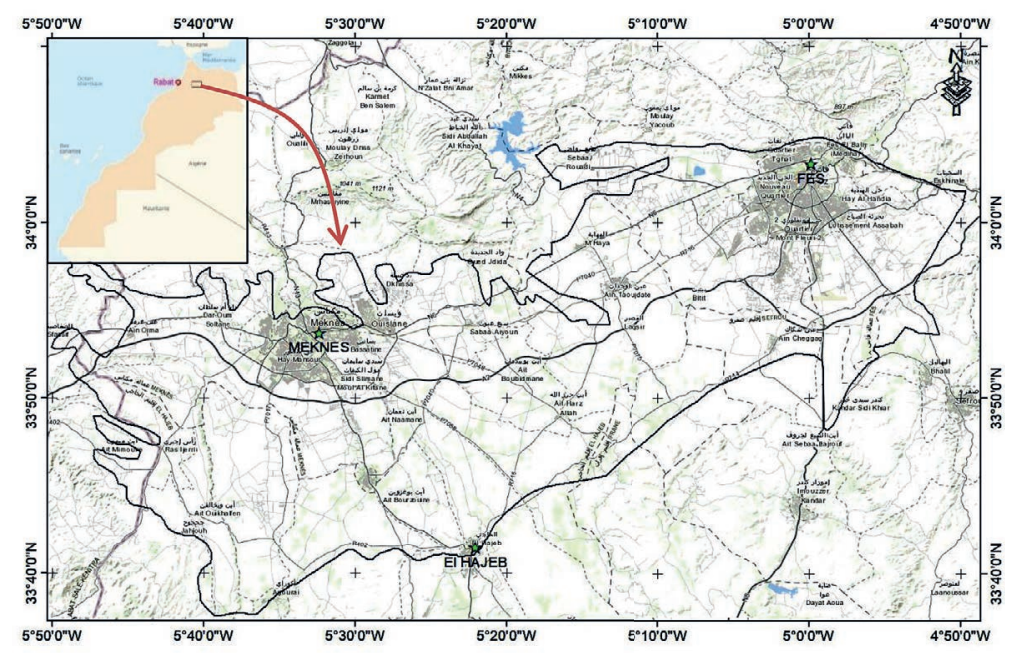

Figure 1. Location of the study area 
Table 1. List of Landsat-5, 7 and 8 satellite images used in this study

\begin{tabular}{|c|c|}
\hline Satellites & Dates \\
\hline \multirow{2}{*}{ Landsat-5 TM } & $02-01-1988$ \\
\hline & 29-08-1988 \\
\hline \multirow{2}{*}{ Landsat-7 ETM } & 19-07-1999 \\
\hline & $26-12-1999$ \\
\hline \multirow{2}{*}{ Landsat-5 TM } & 06-07-2009 \\
\hline & $11-11-2009$ \\
\hline \multirow{12}{*}{ Landsat-8 OLI et TIRS } & 07-01-2019 \\
\hline & 24-02-2019 \\
\hline & 12-03-2019 \\
\hline & 13-04-2019 \\
\hline & 15-05-2019 \\
\hline & 16-06-2019 \\
\hline & 18-07-2019 \\
\hline & 19-08-2019 \\
\hline & 04-09-2019 \\
\hline & 06-10-2019 \\
\hline & 07-11-2019 \\
\hline & 09-12-2019 \\
\hline
\end{tabular}

zero $(\mathrm{K})$. For the extraction of physical parameters from Landsat-5 TM and Landsat-7 ETM images, the pixel values (DN) of the images are converted to spectral radiance $\left(\mathrm{L}_{\lambda}\right)$ at the sensor level. The following equation is used (USGS, 2019b):

$$
\begin{gathered}
L_{\lambda}=\left(\frac{L_{\max \lambda}-L_{\min \lambda}}{Q C A l_{\max }-Q C A L_{\min }}\right) * \\
*\left(Q C A L-Q C A L_{\min }\right)+L_{\min \lambda}
\end{gathered}
$$

where: $L \lambda$ : spectral radiance

$L M A X$ and $L M I N$ : The spectral values contained in the metadata (Table 2).
QCALMAX and QCALMIN: The pixel calibration values contained in the metadata. QCALmin $=1$; QCALmax $=255$; QCAL : $\mathrm{CN}$; Lmin = 0 (BRR), 3,2 (HRR); $L \max =17,04$ (BRR), 12,65 (HRR) ;

\section{Conversion of spectral radiance $(L \lambda)$ into brightness temperature $(\mathrm{Tb})$}

Once the digital counts (DN) are converted to spectral radiance, the thermal infrared sensor (TIR) band data should be converted from spectral radiance to brightness temperature $(\mathrm{Tb})$ (USGS, 2019c) using the thermal constants provided in the metadata file.

$$
\mathrm{Tb}=\frac{\mathrm{K} 2}{\ln \left[\left(\frac{\mathrm{K} 1}{\mathrm{~L} \lambda}\right)+1\right]}-273.15
$$

Where $K 1$ and $K 2$ represent the thermal conversion constants specific to the band $\mathrm{n}$ (Tables 3 and 4). In order to obtain results in degree Celsius, the brightness temperatures is corrected by adding absolute zero $\left(-273.15^{\circ} \mathrm{C}\right)$.

\section{Calculation of emissivity ( $(\varepsilon)$}

The emissivity is then calculated using the following equation (Sobrino et al., 2004).

$$
\varepsilon=(0,004 * \mathrm{PV})+0,986
$$

where: $P V$ : the proportion of vegetation

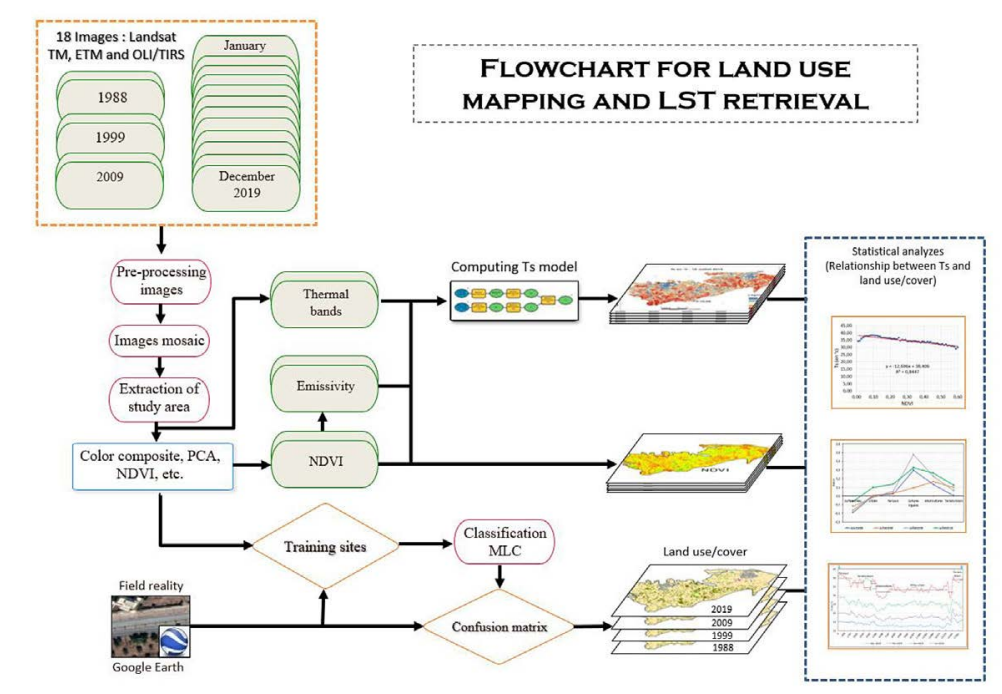

Figure 2. Flowchart for LULC mapping and LST retrieval 
Table 2. Landsat 5 and 7 conversion constants

\begin{tabular}{|c|c|c|c|}
\hline Satellites & Bands & $\mathrm{L}_{\text {MIN }}$ & $\mathrm{L}_{\text {MAX }}$ \\
\hline \multirow{4}{*}{ Landsat ETM } & 1 & 6.2 & 191.6 \\
\cline { 2 - 4 } & 2 & 6.4 & 196.5 \\
\cline { 2 - 4 } & 3 & 5.0 & 152.9 \\
\cline { 2 - 4 } & 4 & 5.1 & 157.4 \\
\cline { 2 - 4 } & 5 & 1.0 & 31.06 \\
\cline { 2 - 4 } & 6 & 3.2 & 12.65 \\
\cline { 2 - 4 } & 7 & 0.35 & 10.80 \\
\cline { 2 - 4 } & 8 & 4.7 & 158.3 \\
\hline \multirow{5}{*}{ Landsat TM } & 1 & -1.52 & 193.0 \\
\cline { 2 - 4 } & 2 & -2.84 & 365.0 \\
\cline { 2 - 4 } & 3 & -1.17 & 264.0 \\
\cline { 2 - 4 } & 4 & -1.51 & 221.0 \\
\cline { 2 - 4 } & 5 & -0.37 & 30.2 \\
\cline { 2 - 4 } & 6 & 1.2378 & 15.303 \\
\cline { 2 - 4 } & 7 & -0.15 & 16.5 \\
\hline
\end{tabular}

$$
\mathrm{PV}=\left(\frac{\text { NDVI }- \text { NDVIs }}{\text { NDVIV }- \text { NDVIs }}\right)^{2}
$$

\section{Conversion of brightness temperature (Tb) to Surface Temperature (Ts)}

After computing the corresponding emissivity values from NDVI values for each pixel, the emissivity corrected land surface temperatures (LST) have been calculated by Artis and Carnahan model (1982).

$$
L S T=\frac{T b}{\left(1+\left[\left(\frac{\lambda T b}{\rho}\right) \ln \varepsilon\right]\right)}
$$

where: LST: the surface temperature in degrees Celsius $\left({ }^{\circ} \mathrm{C}\right)$,

$\mathrm{Tb}$ : the brightness temperature in degrees Celsius $\left({ }^{\circ} \mathrm{C}\right)$,

$\lambda$ : the wavelength of the emitted radiance $(\lambda=10.895)$

$\varepsilon$ : the emissivity

Table 4. Specific thermal conversion constants for band 6 of Landsat 5 and 7

\begin{tabular}{|l|c|c|}
\hline \multirow{2}{*}{ Landsat ETM } & K1 & 666.09 \\
\cline { 2 - 3 } & K2 & 1282.71 \\
\hline \multirow{2}{*}{ Landsat TM } & K1 & 607.76 \\
\cline { 2 - 3 } & K2 & 1260.56 \\
\hline
\end{tabular}

Table 3. Specific thermal conversion constants for Landsat 8 bands 10 and 11

\begin{tabular}{|l|c|c|}
\hline \multirow{2}{*}{ Specific thermal constants (band 10) } & $\mathrm{K} 1$ & 774.8853 \\
\cline { 2 - 3 } & $\mathrm{K} 2$ & 1321.0788 \\
\hline \multirow{2}{*}{ Scale factors (band 10) } & $\mathrm{ML}$ & 0.0003342 \\
\cline { 2 - 3 } & $\mathrm{AL}$ & 0.1 \\
\hline \multirow{2}{*}{ Specific thermal constants (band 11) } & $\mathrm{K} 1$ & 480.8883 \\
\cline { 2 - 3 } & $\mathrm{K} 2$ & 1201.1442 \\
\hline \multirow{2}{*}{ Scale factors (band 11) } & $\mathrm{ML}$ & 0.0003342 \\
\cline { 2 - 3 } & $\mathrm{AL}$ & 0.1 \\
\hline
\end{tabular}

$$
\rho=\mathrm{h} \times \frac{\mathrm{c}}{\sigma}=1.438 \times 10^{-2} \mathrm{~m} \mathrm{~K}
$$

where: $\sigma$ : the Boltzmann constant $(1.38 \times$ $\left.10^{-23} \mathrm{~J} / \mathrm{K}\right)$,

$h$ : the Planck's constant $\left(6.626 \times 10^{-34} \mathrm{~J} \mathrm{~s}\right)$ c: velocity of light $\left(2.998 \times 10^{-8} \mathrm{~m} / \mathrm{s}\right)$

\section{Land use mapping by remote sensing}

For land use mapping, the supervised classification method by maximum likelihood algorithm was employed. The process of land cover mapping consists of several steps. First, the sector is covered by two Landsat scenes (Path-Row) (201-36 and 201-37); therefore, two images were formed to form a single one that covers the entire study region. Then, the collection of training samples was carried out. Six main LULC classes were identified: water bodies, urban, rangelands, irrigated crops, arboriculture and arable lands. The relevance of these samples and the separability of land cover classes are graphically analyzed by point clouds (Figure 3 ). An automatic classification was then performed using the maximum likelihood algorithm.

The accuracy of the classification was assessed using the confusion matrix (Bontemps, 2004). From this matrix, the global precision and the Kappa coefficient were generated. The overall accuracy of the classification is equal to the number of well-classified pixels compared to the total number of pixels probed. The Kappa coefficient reflects the reduction in the error made when using the classification compared to the error that would occur with random assignment of classes. The Kappa coefficient provides an overall assessment of the accuracy of the classification (Yagoub, 2015). 

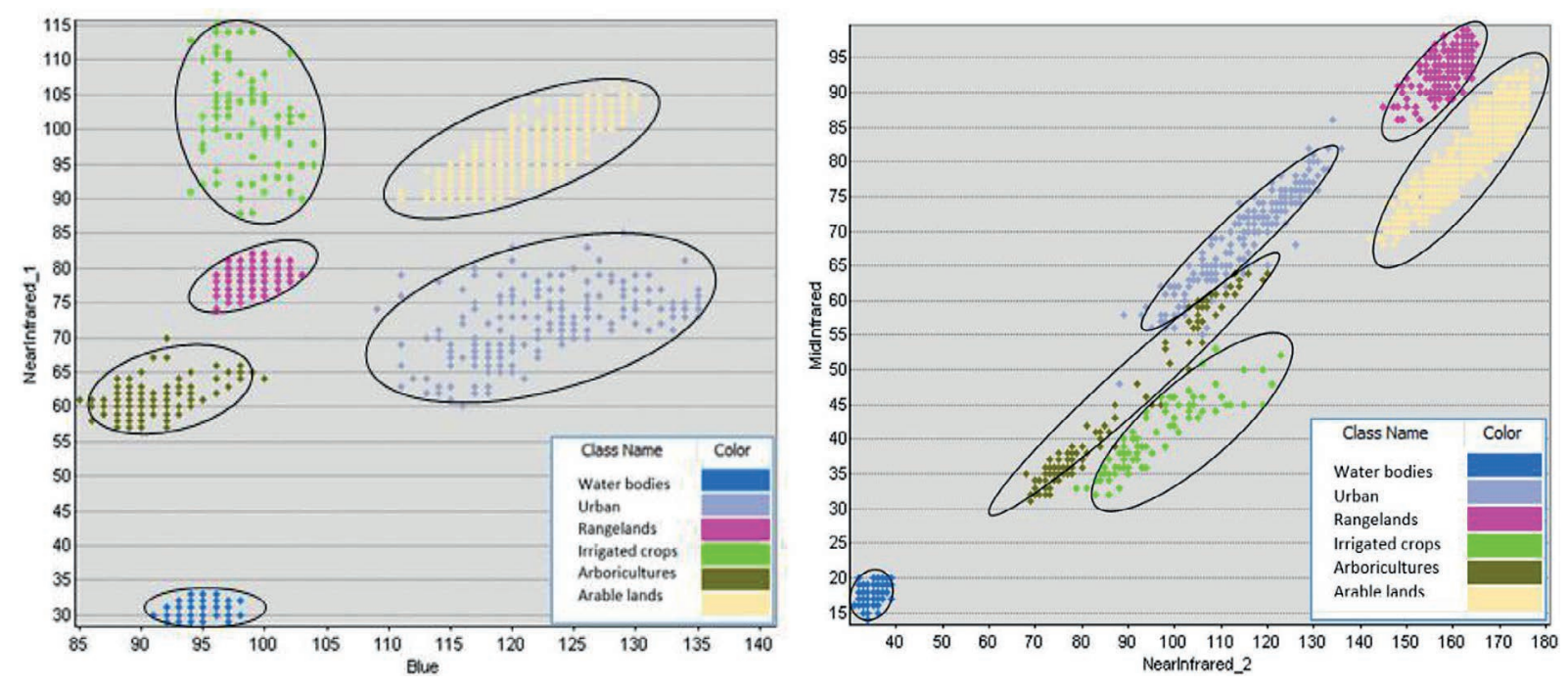

Figure 3. Test of classes separability (sampling sites) by point cloud

\section{RESULTS AND DISCUSSION}

\section{Diachronic study of LULC in Saïss plain}

After pre-treatment, the images were individually classified into six LULC categories: water bodies, urban, rangelands, irrigated crops, arboriculture and arable lands. Before starting the analysis and interpretation of these LULC maps, validation of the classification was performed by visual comparison with field reality and by calculation and analysis of the confusion matrix. In practice, a layer of polygons distributed randomly over the entire study area was generated. A total of 100 samples for the six classes were defined based on the Google Earth images. This layer rasterized thereafter will be used as field data. An operation of intersection of this layer with that resulting from the classification was made to obtain a layer in which the points are assigned to their LULC class. Using a SQL query in ArcGIS software, the data for the confusion matrix was extracted. The percentage of overall accuracy and the Kappa coefficient for all classifications exceed $80 \%$. This suggests that the classifications are reliable and usable (Bonn, 1996; El Hadraoui, 2013) (Table 5). In order to improve the classification, a post-classification processing was conducted (application of a majority filter). Indeed, due to the quality of the image ( $30 \mathrm{~m}$ pixel) and the processing process (each pixel is processed individually), the classified image by the maximum likelihood method may incorrectly classify some cells (noise random) and create small incorrect regions. Therefore, to improve the classification, it is advisable to use a majority filter. The resulting map from the application of this cleaning tool is more aesthetic.

The classification results for the four years show a significant change in the LULC classes (Figure 4). The dynamics of LULC in the region between 1988 and 2019 is marked mainly by a decrease in rangelands, irrigated crops and arable lands, and an increase in urban, water bodies and arboriculture.

The result analysis shows that the arable land class covers more than $77 \%$ of the total area during the four observation years but with a significant drop of 5.6\% between 1988 and 2019. The urban area covers about $6.5 \%$ of the territory on 2019 while 30 years earlier (1988) it only $2.7 \%$. This period was also marked by a remarkable increase in the urban area which increased by $140 \%$ during this period. The water bodies are also increasing, and this change depends not only on the natural conditions of rainfall but also on the construction of two dams to protect Fez against floods (El Gaada Dam and Mehraz Dam) and on the irrigation activities (creation of several water storage basins). The results also show a significant increase (more than $43 \%$ ) of arboriculture

Table 5. Overall accuracy and Kappa coefficients of images classification

\begin{tabular}{|c|c|c|}
\hline Year & Overall accuracy (\%) & Kappa coefficient \\
\hline 1988 & 84.18 & 0.81 \\
\hline 1999 & 86.15 & 0.83 \\
\hline 2009 & 84.18 & 0.81 \\
\hline 2019 & 84.32 & 0.80 \\
\hline
\end{tabular}




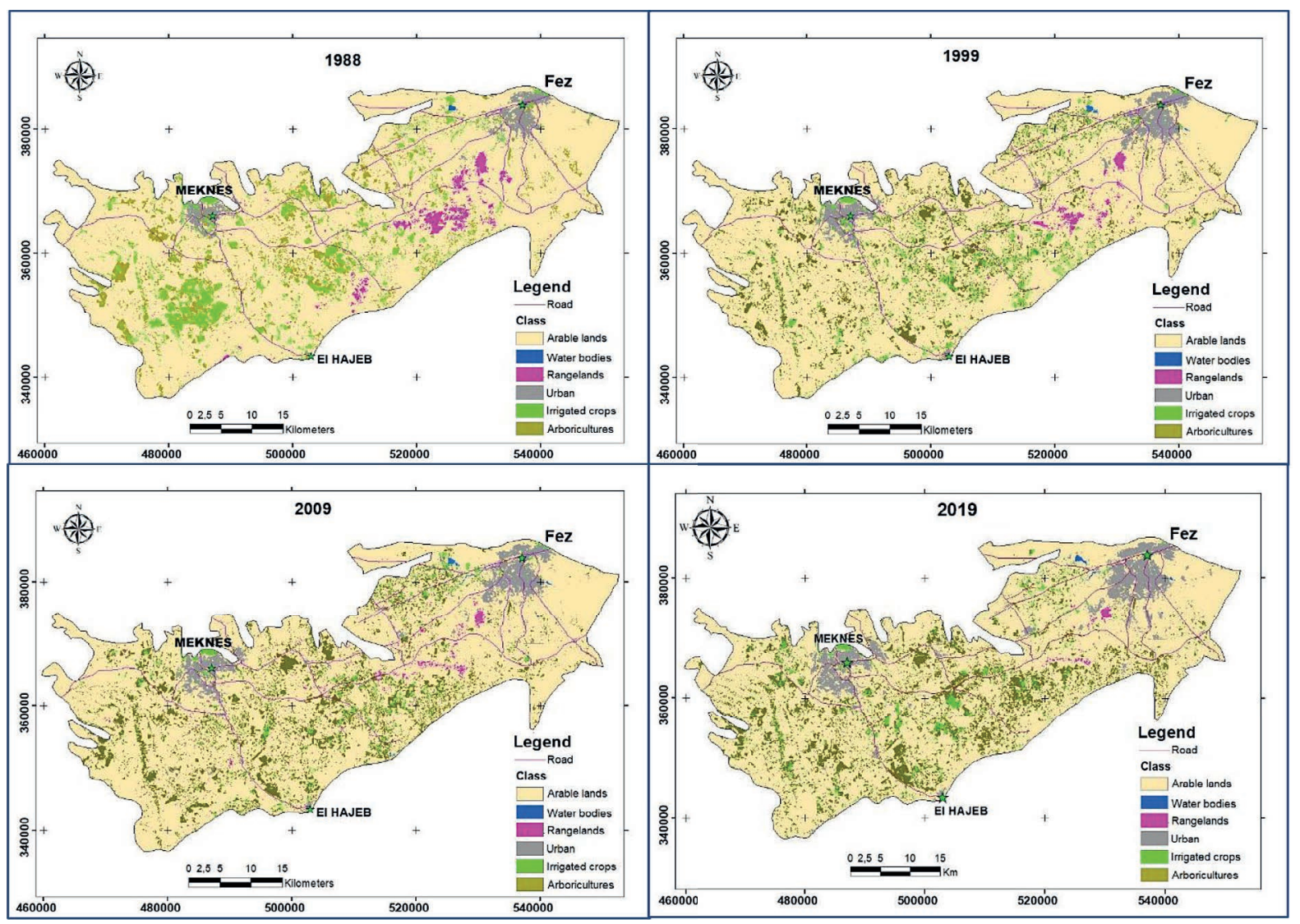

Figure 4. LULC maps for 1989, 1999, 2009 and 2019

(fruit plants and olive trees mainly). Rangelands show a significant decrease $(-82 \%)$ and this is due to cultivation and/or urbanization activities.

\section{Determination of LST in Saïss plain}

Figure 5 below shows the maps of LST in Saïss Plain during the four seasons of 2019. Figure 6 shows the maps of LST in Saïss Plain during the winter and summer of 1988, 1999, 2009 and 2019. Throughout the region, there is a strong thermal heterogeneity: between urban, agricultural, water bodies, etc. (from $-4^{\circ} \mathrm{C}$ to $46^{\circ} \mathrm{C}$ ). The cool zones are well individualized and correspond to urban and arboriculture landscapes. The warm zones correspond to agricultural land and rangelands.

\section{Relationship between LST and vegetation index}

In order to highlight the effect of biomass on LST distribution, the Normalized Vegetation Index (NDVI) was calculated, which is a very good indicator of biomass. The result of the correlation between LST and NDVI is represented in two ways. Firstly, the correlation between LST and NDVI for 1988, 1999, 2009 and 2019 with one image in winter and one image in summer for each year (Figure 7). In a second step, the correlation between LST and NDVI over 2019 (one image per month) (Figure 8). In all cases, it can be seen that there is a negative correlation between the LST and the vegetation index with very high correlation coefficients that can reach 0.93 .

For 2019, in all graphs, it was noted that for low NDVI (between 0 and 0.1 corresponding to dry bare soil) an increase in LST occurs. From the NDVI values above 0.1, LST decreases as the NDVI values increase, which is quite normal because the increase in biomass reduces the heat release from the surface.

\section{LST variations for different LULC types for the period 1988-2019}

In order to explain the variation of LST for the same land cover over time (Figure 9), graphs were created. LST increases slightly from water bodies to arable lands over years (Highest in November 2009 and lowest in January 1988) and it is explained by the variation air temperature during these days. For the summer season, LST is 


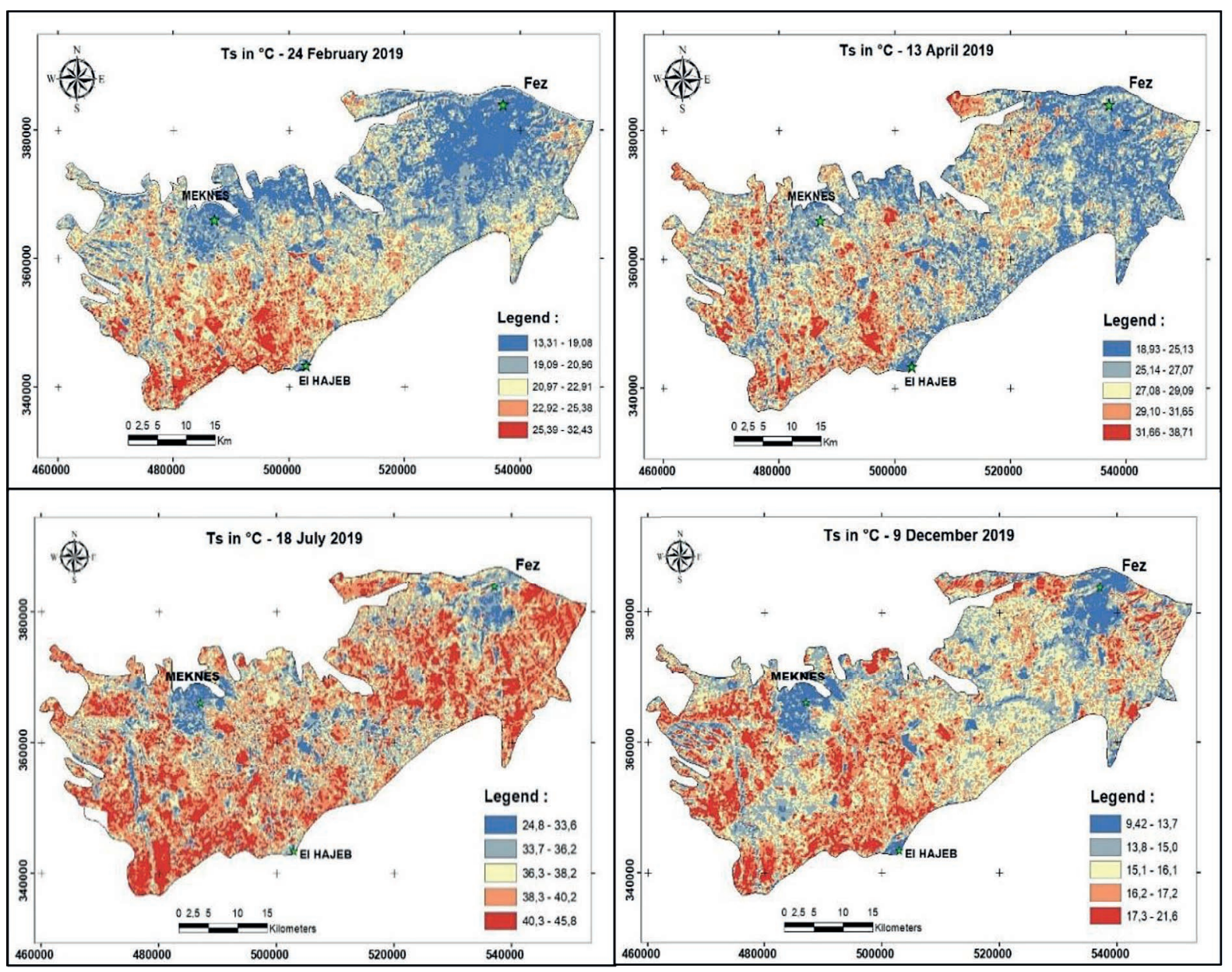

Figure 5. LST maps for the four seasons of 2019

low for water bodies, irrigated crops and arboriculture, whereas for rangelands and arable lands it is quite high.

\section{LST variations for different LULC types during 2019}

In order to highlight the effect of LULC change on LST over seasons a graph for change for 2019 was plotted (Figure 10). From this presentation, it can be seen first of all that LST show a general variation according to the climate of the region characterized by four seasons (cold winter, warm summer and moderate spring and autumn). This general variation follows the same pattern as the variation in air temperatures in the region over the year (Figure 11). In addition to LST variation over time, there is a variation with LULC for each month of 2019. It can see that LST increases from water bodies, irrigated crops, arboriculture, urban areas, rangelands and arable lands. Urban areas, rangelands, and arable lands correspond to high LST.
Among the remarks regarding this study of LST and its relationship with LULC, there are no islands of heat visible in urban area in relation to their surroundings peri-urban or agricultural areas.

\section{LST variation for different LULC types according to AB transect for 2019}

A cross-section (AB transect) was made across the study area to represent the LST variation for different LULC types, (Figure 12). The cross-section profile (Figure 13) for July 2019 (Summer Season) shows that water bodies, urban and arboriculture have average LST between $32^{\circ} \mathrm{C}$ and $34^{\circ} \mathrm{C}$, while rangelands and arable lands have mean LST between $37^{\circ} \mathrm{C}$ and $40^{\circ} \mathrm{C}$. During this month, there is a coefficient of variation of LST between water bodies and arable land with a 17\% variation. In April 2019 (Spring season), the differentiation of LULC classes from the point of view LST is less evident compared to July. LST values are low in general but with less difference 


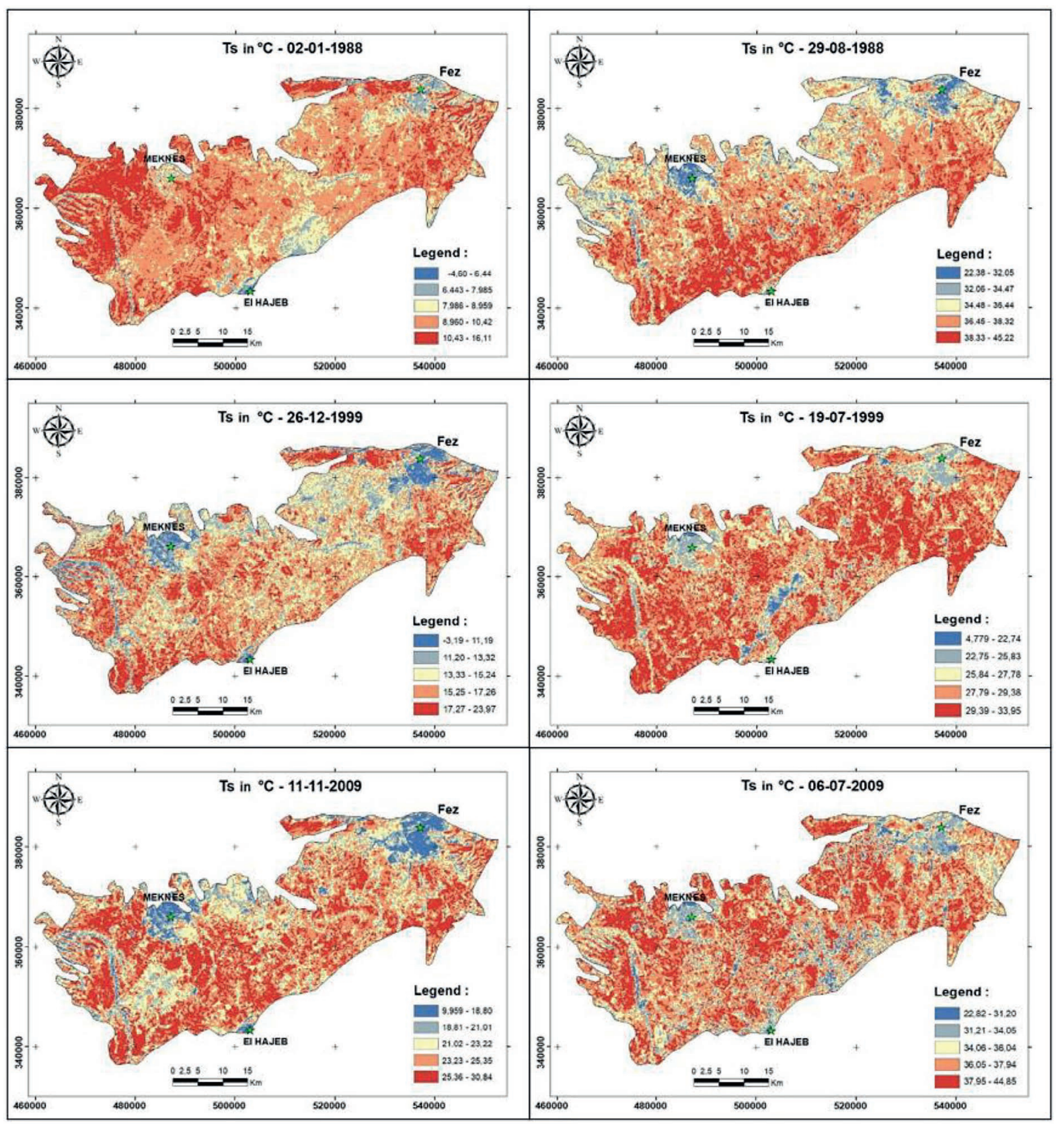

Figure 6. LST maps during winter and summer of 1988, 1999 and 2009

between LULC classes. For other seasons (December: autumn and February: winter) the differentiation of LULC classes from the point of view LST is even less clear.

\section{CONCLUSIONS}

The modification of vegetation cover has an important consequence, particularly on the hydrology and the land surface temperature in the Saïss plain. In order to quantify the amplitude of LST linked to land use land cover change at the local and regional scale, several maps of LST and
LULC for the period (1988-2019) were produced in the framework of this study.

In order to analyze the evolution of LULC in relation to cultivation practices in the study area, remote sensing data is the most appropriate tool. Numerous vegetation indices combining red and near infrared channels such as the NDVI (Normalized Difference Vegetation Index) have proved their interest in studying biomass. The time series of this index allow temporal monitoring of the vegetation cover representative of plant growth, which is both an indicator of LST as a response of LULC conditions. Thus, the NDVI index can serve as an indicator of changes in LULC like an 


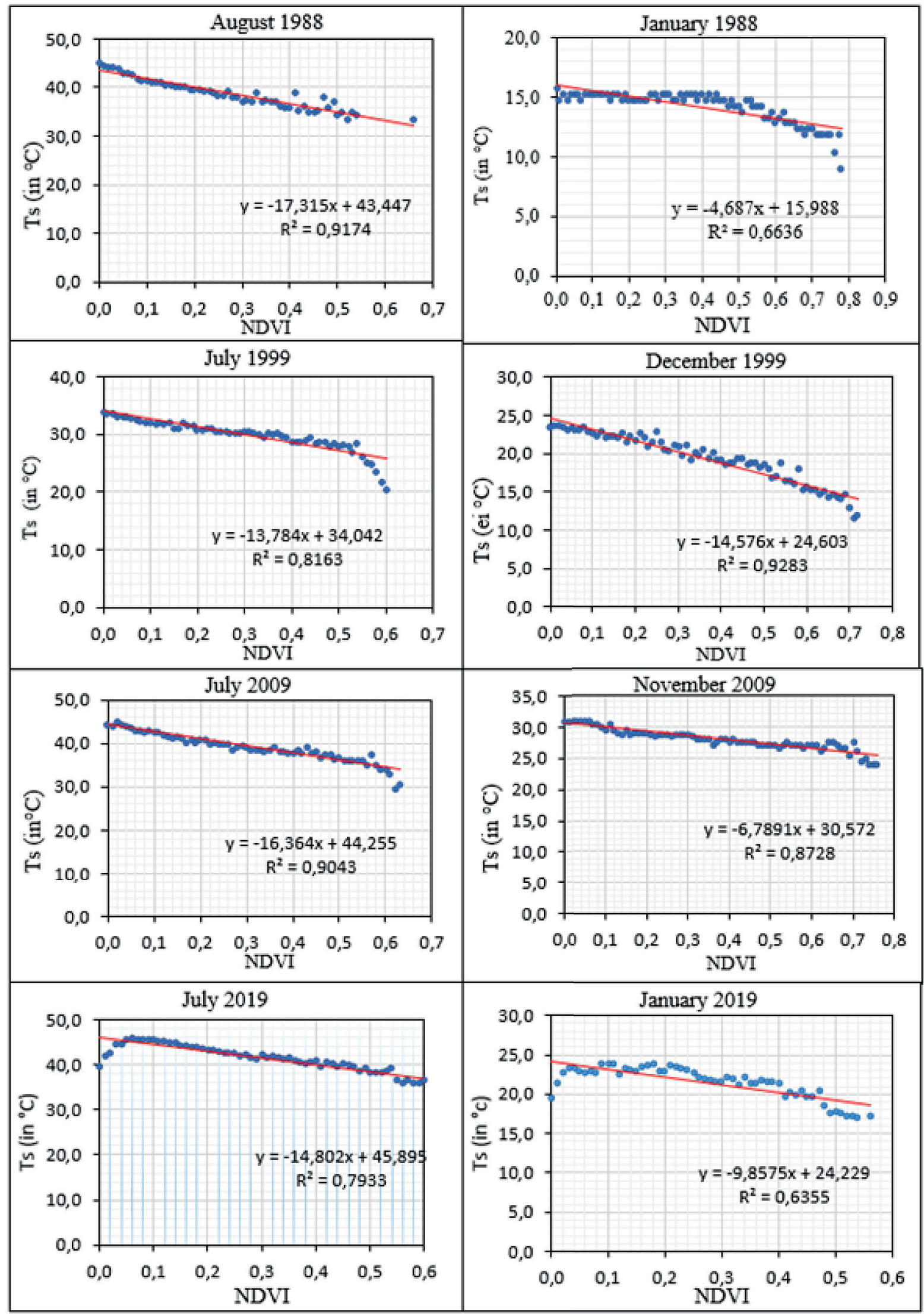

Figure 7. Correlation between LST and NDVI for 1988, 1999, 2009 and 2019 (one image in winter and one image in summer) 
a)

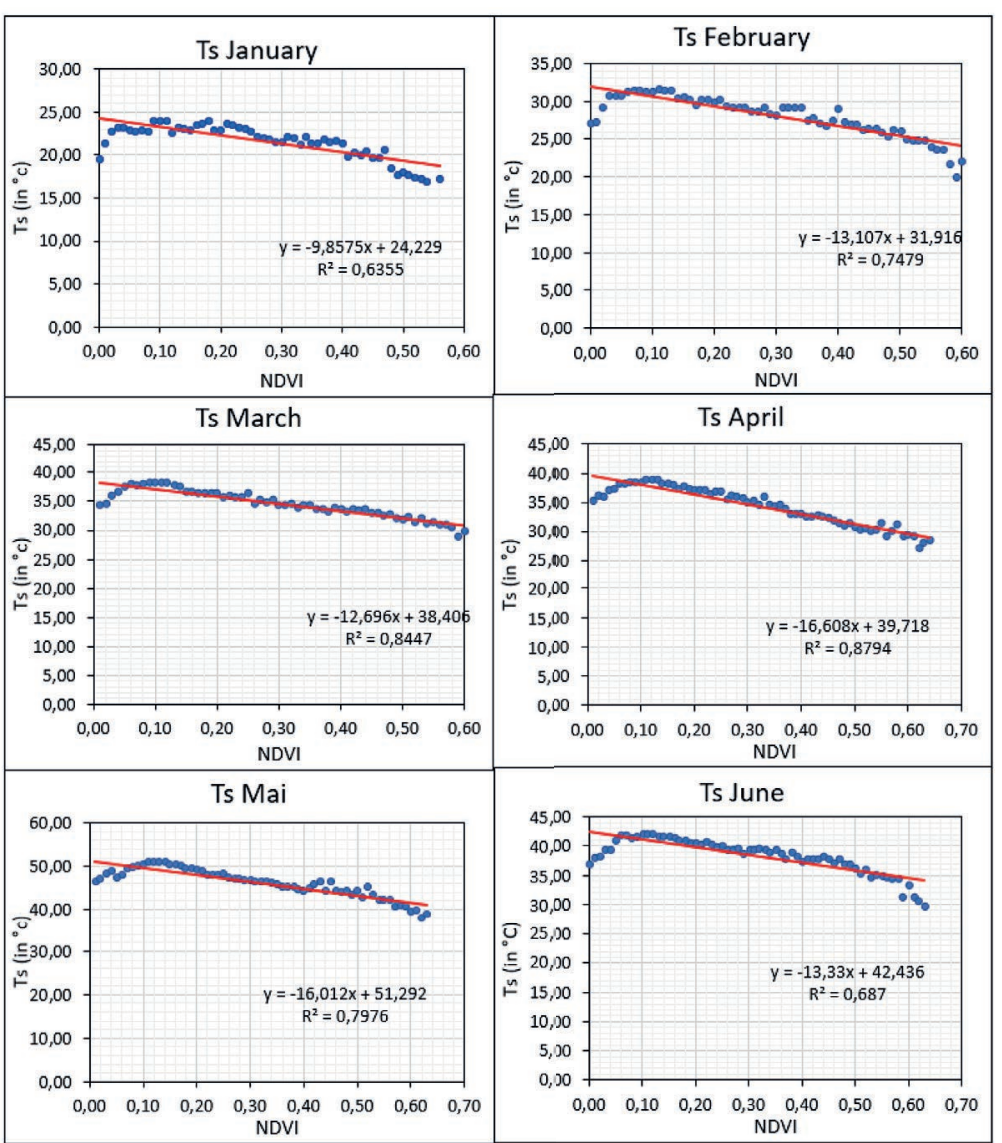

b)
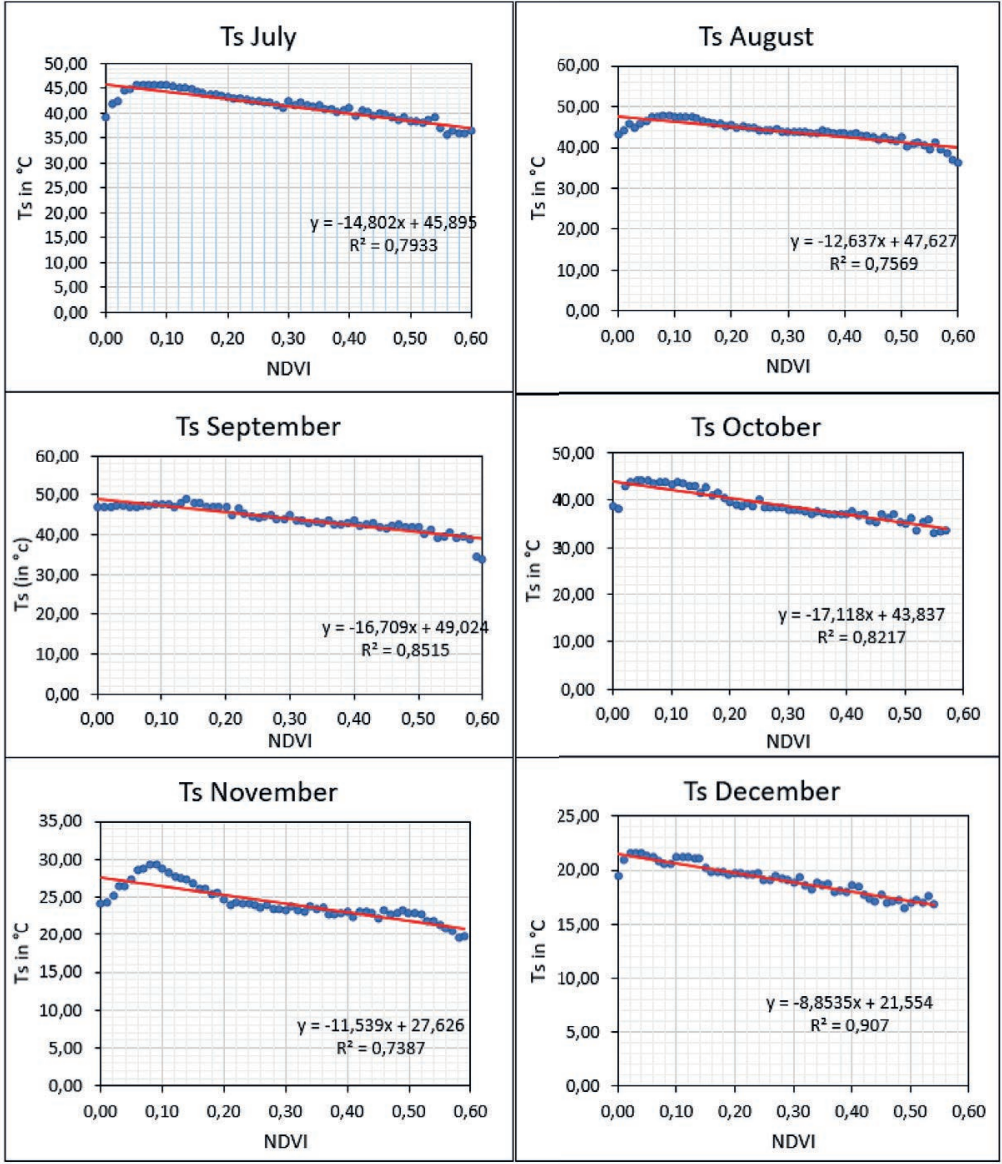

Figure 8. Correlation between LST and NDVI over 2019 (One image per month) 

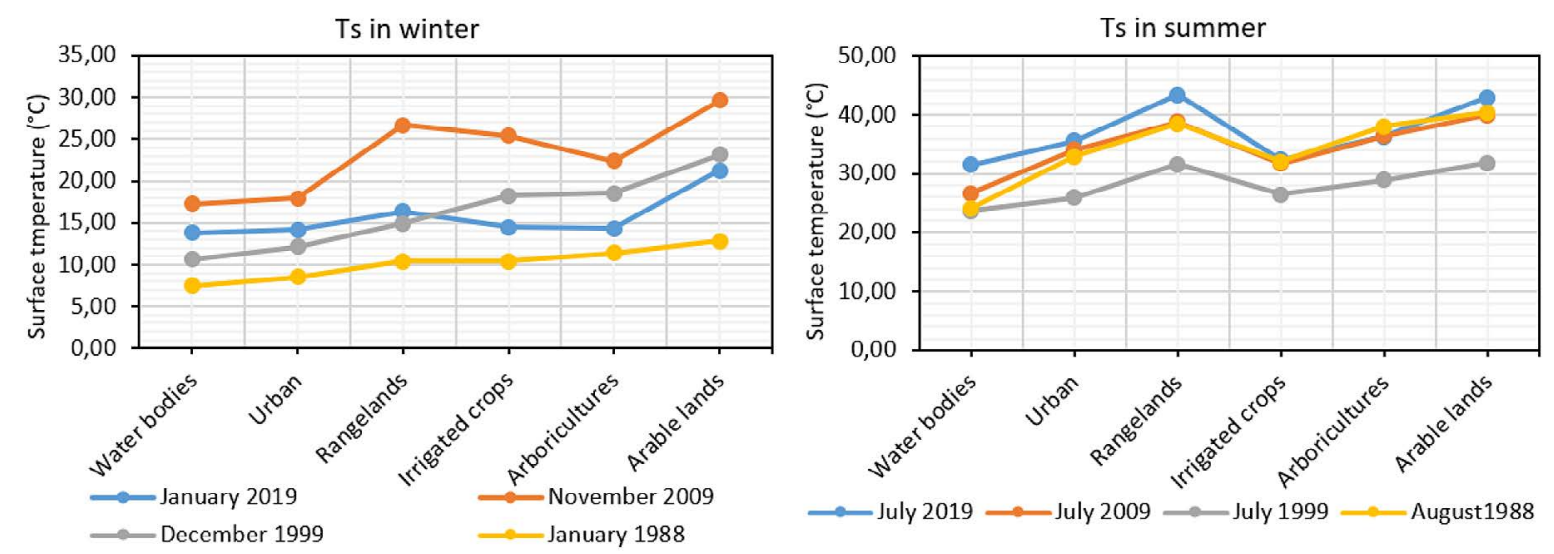

Figure 9. LST variation for different LULC over time (For winter and summer seasons)

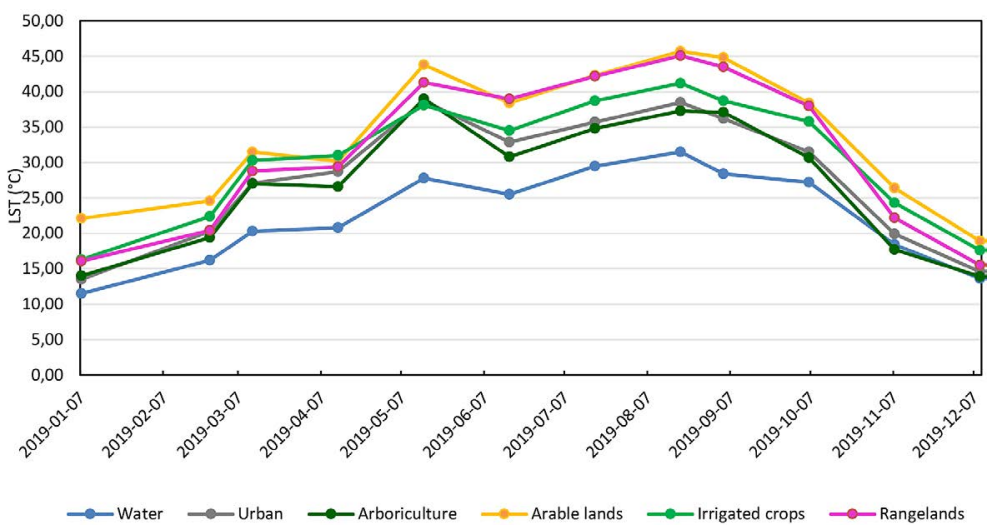

Figure 10. LST variation for different LULC types during 2019

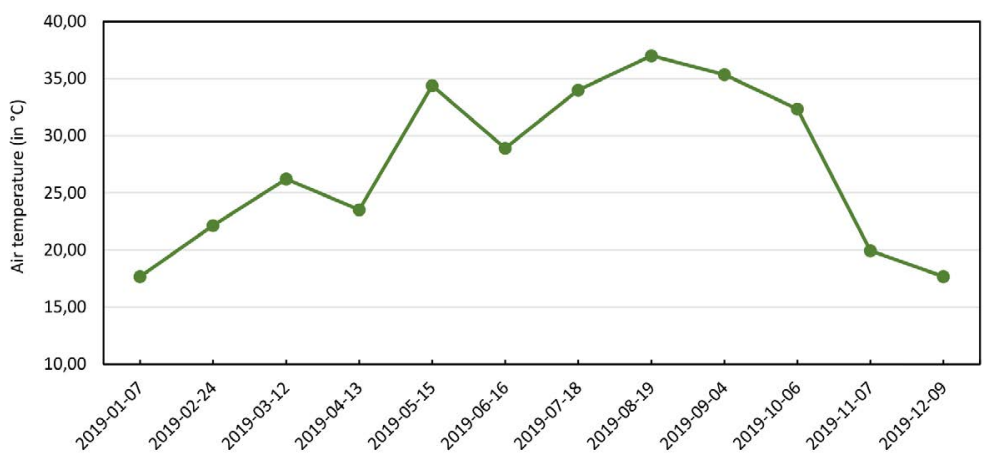

Figure 11. Variation of air temperature for 2019 (Average of Fez and Meknes stations)

intensification of urbanisation and agricultural practices. This classification is done for making a relationship between NDVI of different intensity levels, LST and changing cropping pattern,

Results show that the sectors where bare soil is dominant have high LST, compared to those where the plant cover is dominant or in urban. On the basis of these maps, the analysis of the spatio-temporal changes in LULC over the period 1988-2019 was carried out. LULC in Saïss plain has undergone significant changes over the past 30 years. There is an increase of arboriculture and urban areas to the detriment of arable lands and rangelands. The relationship between LST and LULC for the period 1988-2019 shows that the surface temperature varies during phases of plant growth in all seasons and that it is diversified due to the positional influence of the type of the existing LULC. In general, the modification of land use/cover with regard to urbanization and the exchange of arable lands in arboriculture are the main causes of the change in surface temperature in the study area. 


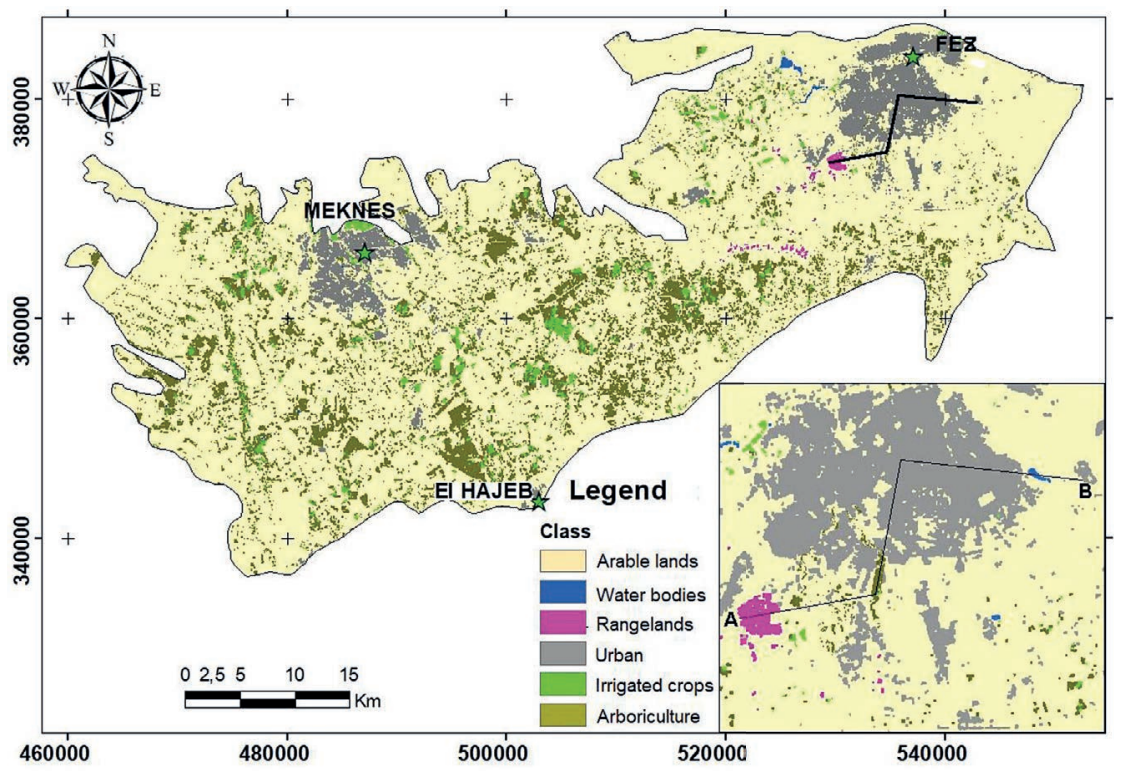

Figure 12. Geographical location of the $\mathrm{AB}$ transect

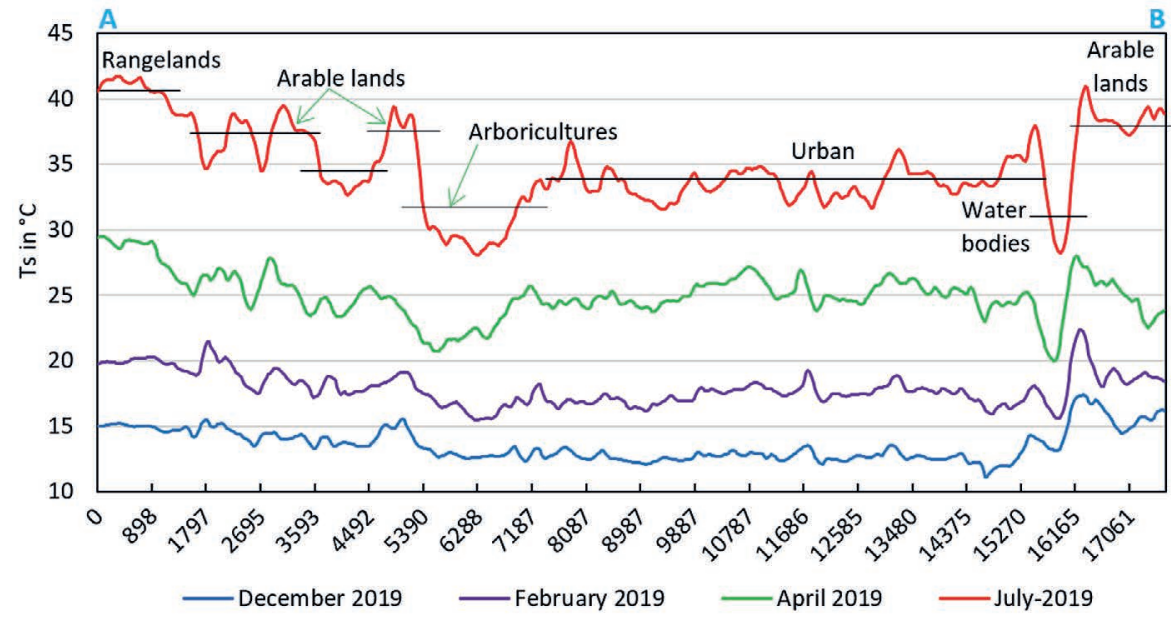

Figure 13. LTS profiles for different LULC types during 2019 along the AB transect

\section{REFERENCES}

1. Artis, D.A., Carnahan, W.H. (1982). Survey of emissivity variability in thermography of urban areas. Remote Sens. Environ. 12, 313-329.

2. Bhaga, T.D., Dube, T., Shekede, M.D., Shoko, C., (2020). Impacts of Climate Variability and Drought on Surface Water Resources in Sub-Saharan Africa Using Remote Sensing: A Review. Remote Sens. 12, no. 24: 4184. https://doi.org/10.3390/rs12244184.

3. Bonn, F. (1996). Précis de télédétection, Volume 2 - Application thématiques. Presses de l'Université du Québec/ AUPELF, 633.

4. Bontemps S. (2004). Cartographie et interprétation de l'évolution du développement territorial par télédétection spatiale au Cambodge. Mémoire de fin d'études de la faculté des Sciences Agronomiques, UCL, Louvain-La-Neuve, 111.
5. Courault, B., Seguin, \& Olioso, A., (2005). Review on estimation of evapotranspiration from remote sensing data: From empirical to numerical modeling approaches. Irrig Drainage Syst 19, 223-249. https://doi.org/10.1007/s10795-005-5186-0.

6. El Hadraoui Y. (2013). Étude diachronique de l'occupation du sol et de modélisation des processus érosifs du bassin versant du Bouregreg (Maroc) à partir des données de l'Observation de la Terre. Mémoire d'Ingénieur CNAM, École Supérieure des Géomètres et Topographes, 89.

7. Feddema, J.J., Oleson, K.W., Bonan, G.B., Mearns, L.O., Buja, L.E., Meehl, G.A. et Washington, W.M. (2005). The importance of land-cover change in simulating future climates. Science, 1674-1678.

8. Joshi, R.C., Ryu, D., Sheridan, G.J., and Lane, P.N. J., A new Remote Sensing-based vegetation water stress index: Temperature Vegetation Water Stress 
Index (TVWSI), EGU General Assembly, (2020), Online, 4-8 May 2020, EGU2020-12308, https:// doi.org/10.5194/egusphere-egu2020-12308.

9. Li, Z.L., Tang, B., Wu, H., (2013). Satellite-derived land surface temperature: Current status and perspectives. Remote Sensing of Environment 131, pp 14-37.

10. Nivedha D.S., Jasmineniketha M., Geetha P. and Soman K.P. (2017). Agricultural drought analysis for Thuraiyur taluk of Tiruchirappali District using NDVI and land surface temperature data. 11th International Conference on Intelligent Systems and Control (ISCO), Coimbatore, 155-159.

11. Qin, Z., and Karnieli, A., (1999). Progress in remote sensing of land surface temperature and ground emissivity using NOAA-AVHRR data. Inter. J. of Rem. Sens 20: 2367-2393.

12. Sajjad, K.Ajay, H. Stephen, (2009). Estimating soil moisture using remote sensing data: A machine learning approach, Advances in Water Resources, Volume 33, Issue 1, pp.69-80,( 2010), https://doi.org/10.1016/j.advwatres10.008.

13. Schmugge, T.J., Kustas, W.P., Ritchie J.C., Jackson T. J. and Al Rango. (2002). Remote sensing in hydrology. Advances in Water Resources, 25 (12), 1367-1385.
14. Sobrino, J.A., Jiménez-Munoz, J.C. et Paolini, L., (2004). Land surface temperature retrieval from Landsat TM5. Remote Sensing of Environment, no. 4, vol 90, 434-440.

15. USGS, (2019a). Landsat collection 1 level 1 product definition. EROS Sioux Falls, South Dakota, USA, 32.

16. USGS. (2019b). Landsat 8 (L8) Data Users Handbook Version 5.0. EROS Sioux Falls, South

17. USGS. (2019c). Landsat 7 (L7) Data Users Handbook Version 2.0. EROS Sioux Falls, South Dakota, USA, 114.

18. Yagoub. H., (2015). Cartographie et suivi du couvert végétal des zones semi-arides par l'imagerie satellitaire. Doctorat Es-Science, Université des Sciences et de la Technologie d'Oran Mohamed Boudiaf, Faculté de Physique, 150.

19. Yu M. and M. Cheng., (2010). Ts/NDVI space based drought monitoring study from satellite remote sensing data in Heilongjiang. 2010 World Automation Congress, Kobe, 23-28.

20. Zhou, J., Li, J., Zhang, Li., Hu, D. and Zhan, W., (2012). Intercomparaison of methods for estimating land surface temperature from Landsat-5 TM image in an arid region with low water vapor in the atmosphere. International Journal of Remote Sensing 33(8), 2582-2602. 